\title{
A Qualitative Investigation Into the Impact of the Basketball Learning Intervention Programme (BLIP) on Disengaged Secondary School Students in the United Kingdom
}

\author{
${ }^{1}$ School of Health, Sport and Bio Science University of East London \\ *Corresponding author: j.beale@uel.ac.uk
}

Lukas VOLSKIS $^{1}$ (D) Richard HUNT $^{1}$ and James Trevor BEALE ${ }^{1 *(D)}$

\begin{abstract}
This paper will evaluate the longitudinal effects of a basketball based intervention programme that targeted ten disengaged male secondary school students at a school in the Kent, England. The programme aimed to improve the behaviour and academic performance of the participants through a weekly intervention carried out by an external basketball player and coach providing academic support, mentoring and specially designed basketball sessions. Sports interventions have been deemed to provide a positive short-term impact on young people. However, researchers have identified the need for a longitudinal approach in order to examine the effects of such interventions post involvement as supported. This study involved five former Basketball Learning Intervention Programme (BLIP) members (with a mean age of $16.4 \mathrm{SD} \pm 0.55$ years) that were interviewed using semi-structured interview approach, 12 months after completing the intervention. Interpretative Phenomenological Analysis (IPA) revealed four superordinate and eleven subordinate themes. The four supeordinate themes were; 'baseline behaviours pre-intervention', 'immediate outcomes of the BLIP', 'impact of the coach' and 'long standing transferable outcomes'. The results revealed an immediate impact in comparison to the baseline behaviours of the participants pre-intervention. The data suggested that one of the most effective aspects of the programme was the positive impact of the coach on the participants. More importantly, this is the only study to report long-term improvements amongst the participants in terms of behaviour and academics as a result of engagement in a sports based intervention.
\end{abstract}

Keywords

Antisocial Behavior, Basketball, IPA, Sport As The Social Instrument, Sport, Education

\section{INTRODUCTION}

\section{Physical Activity, Anti-social Behaviour and Academic Achievement}

Sandford et al. (2008) supports the impact of physical activity in relation to tackling anti-social behaviour amongst young people within the United Kingdom (UK) which is a concerning issue that sometimes leads to the resignation of school teachers (Hayden, 2011). Recently, a number of initiatives have been developed aiming to reengage disaffected pupils through physical activity (Sandford et al. 2008). Physical activity and sport can play a vital role in assisting the cognitive development process amongst young people as stated by Lista and Sorrentino (2010). Inadequate cognitive development is linked to young people engaging in anti-social behaviour and poor academic performance (Farrington, 2005). Structured support should be put in place to assist the young people exhibiting anti-social behaviour, especially with the UK experiencing the highest rates of anti-social behaviour in Western Europe (ADT, 2006).

Australia emphasises the use of physical activity to prevent anti-social behaviour amongst young people highlighted by the Australian Institute of Criminology evaluating a number of sport based 
programmes that were accessed by young people at risk of being exposed to anti-social behaviour (Morris et al. 2003). The UK has taken a similar approach with various programmes being implemented within a number of schools (Sandford et al. 2008). One of the most successful programmes, the 'Sky Living For Sport' programme, is based on using physical activity to re-engage disengaged young people in education (Sandford et al. 2008). Such programmes focus on cognitive development amongst students and aim to reduce anti-social behaviour and improve academic performance (Sandford et al. 2008).

Pupils improved in terms of behaviour and academic performance whilst taking part in various programmes (Sandford et al. 2008) this supports research by (Morris et al. 2003) showing positive short-term improvement in participant behaviour. This suggests that physical activity facilitates positive behaviour and academic achievement amongst young people. However, to date studies have not taken a longitudinal approach and as such are not able to comment on the longterm impact of such interventions (Bull and Beale (2012).

Sandford et al.(2008) and Morris et al. (2003) present similar results in relation to physical activity impacts on anti-social behaviour and academic work. Morris et al. (2003) states that physical activity interventions reduce anti-social behaviour. Sandford et al. (2008) supports this by highlighting an immediate short-term positive impact of physical activity on anti-social behaviour and academics. However, these studies do not consider the contrasting impacts of different sports. Bull and Beale (2012) state that a boxing intervention, for example, could have negative effects as young people exhibiting anti-social behaviour were taught combat skills. This could be an issue if participants were exposed to hostile situations outside of the intervention. In contrast, a basketball intervention would not present such an issue. Sandford et al. (2008) and Morris et al. (2003) report that the data gathered does not truly represent the full sample of participants and programmes that were evaluated due to a limited number of evaluations of varying quality. Furthermore, the results collected by Sandford et al. (2008) were only gathered from programmes that were deemed to be successful. Both studies failed to incorporate incompleted programmes and participants that elected to leave the interventions.
Literature surrounding physical activity interventions indicates the need for long-term studies. Sandford et al. (2008) and Morris et al. (2003) report positive effects during interventions but fail to report any long-term effects regarding behaviour and academic performance post intervention. Therefore, the true effects of sports interventions must be evaluated through longitudinal studies (Sandford et al. 2008), (Morris et al. 2003) which is also suggested by Bull and Beale (2012). Longitudinal studies could evaluate whether sports interventions can encourage longterm personal development. Therefore, building on current literature in order examine the longitudinal effects of sports interventions makes this study unique amongst literature surrounding the impact of sports interventions.

\section{Sport as a Social Instrument}

Utilising sport as a social instrument can be beneficial to different communities. Various UK Governments have emphasised social inclusion and community renewal through participation in sport (Houlihan and Green, 2013). Tony Blair, in particular, had very strong views on the relationship between sport and community cohesion (Houlihan and Green, 2013). Furthermore, participation in sport can improve the quality of life amongst individuals and communities (Coalter, 2005).

Participation in sport benefits communities with individuals engaging in physical activity becoming $14.1 \%$ more likely to report good health (Fujiwara et al. 2014) which supports research by Coalter (2005). Fujiwara et al. (2014) also state that individuals participating in sport are $11 \%$ more likely to actively seek employment, which relates to the current study with participants choosing to engage in further education or employment. Using sport, as a social instrument is especially significant within neighborhoods that suffer from crime and deprivation as supported by Houlihan and Green (2013). There is evidence to suggest that the BLIP was useful to the participants involved in this study due to the demographics of the community in question. The current study also provides an unique longitudinal investigation on the impacts of sport as a social instrument in relation to the participants as suggested by Fujiwara et al. (2014). 


\section{Basketball Intervention Programmes, Youth Crime Statistics and Demographics}

There is limited literature on the impact of basketball interventions on anti-social behaviour and academic achievement and basketball interventions are predominantly based in the United States. The Boston Celtics of the NBA and the 'Midnight Basketball Leagues' in America's urban areas (Hartman and Depro, 2006) have established the two most prominent interventions. 'Stay in School' (Boston Celtics, no date) is based on providing role models to inspire students to stay in school, as children tend to be inspired by athletes (Biskup and Pfister, 1999). However, this project does not address anti-social behaviour, is not linked to urban areas and does not track changes in participant behaviour.

The 'Midnight Basketball Leagues' aim to combat criminal behaviour within communities experiencing high crime rates (Hartman and Depro, 2006). This relates to Morris et al. (2003) in terms of providing a positive activity for young people within deprived urban communities. Communities engaging in the 'Midnight Basketball Leagues' experienced reduced crime rates which signifies the impact of physical activity on anti-social behaviors (Hartman and Depro, 2006). Furthermore, this programme relates to basketball participation amongst young people within communities similar to Swanscombe, which show the highest participation rates amongst males (Kelley and Carchia, 2013). These two programmes suggest that basketball participation and role models can be used to address anti-social behaviour and academic performance amongst young people within communities that are most vulnerable to anti-social behaviour. Swanscombe, the community where the BLIP took place, is one of the most deprived communities in Kent (Kent County Council, 2011) and experiences one of the highest crime rates in Dartford, Kent with antisocial behaviour responsible for $45 \%$ of all crime (UKCrimeStats, 2014). The BLIP was established at a School in Swanscombe in order to tackle antisocial behavior both within the school and the community. Basketball interventions can be used to support young people that may be exposed to criminal activity and negative behaviour in school (Hartman and Depro, 2006). Therefore, the BLIP was devised on the structures of the Boston Celtics
'Stay in School' project and the Midnight Basketball Leagues within the United States.

\section{The Basketball Learning Intervention Programme (BLIP)}

The BLIP was designed by the staff at the School and commenced in October 2012. The programme aimed to help struggling Year 11 male pupils in regards to inappropriate behaviour and academic achievement. The participants were selected based on behaviour and academic records between Year 7 and Year 10 and it was decided that external help may be needed for the intervention. The school contacted a local professional basketball club, about the possibility of involving a basketball player to become a coach and mentor during the intervention as previous research suggests young males see athletes as role models (Biskup and Pfister, 1999) and (Boston Celtics, no date). The basketball club suggested one of the players for the intervention who is the author in the current study.

Deprivation within the community was one of the main reasons for the intervention as young people from lower socioeconomic backgrounds report low physical activity participation (Dagkas and Stathi, 2007). Low physical activity participation has been demonstrated to result in low stimulation levels and leads to young people engaging in anti-social behaviour (Connor, 2012). The BLIP provided a positive role model and created an opportunity to participate in a positive activity, which could facilitate personal development and positive behaviour (Hagger et al. 2001).

The BLIP occurred Wednesdays between October and April, based around the school day between 08:30 and 15:00. The participants received a modified timetable which incorporated the intervention within regular school hours. Participants received support during Mathematics, English and Science lessons with the coach attending lessons with each participant in 15minute segments. There was an hour-long mentoring session led by the coach to address any behavioural or academic issues. Lastly, a specialist basketball session was put in place to aid the cognitive development of young people as suggested by Dagkas and Stathi (2007). 


\section{METHODOLOGY}

\section{Participants}

The study involved five former Year 11 male students (mean age 16.4 $\mathrm{SD} \pm 0.55$ years). The selected participants successfully completed the BLIP, an intervention facilitated by a basketball coach, providing support in English, Mathematics and Science lessons along with weekly basketball sessions. The participants were of White British ethnicity from a deprived lower class community. Purposive sampling was used to identify the five participants from the total of ten students that took part in the intervention.

\section{Procedure}

The participants took part in $25-35$ minute individual semi-structured interviews in order to provide detailed reflections following the intervention. Consent Forms along with Assent Forms were completed and signed before any interviews were conducted. Each participant took part in an individual interview that was conducted within the library of the school. The interviews took place in a private area of a public place, which was the 'silent study' room within the library and carried out by the researcher of this study.

The interviews were conducted using a semi structured interview schedule. Probing questions were used in order to facilitate the interviews with different participants as supported by Smith (2009). Interview topics and probing questions were altered to create a new interview schedule following a pilot interview as the pilot interview failed to provide sufficient insight about the participants' experiences.

\section{Data Analysis}

Interpretative Phenomenological Analysis (IPA) was used in order to significantly examine the processes of how the participants made sense of the BLIP. IPA allowed the researcher to examine participant experiences of the BLIP as it was assumed to be a significant life experience in the participants' lives as supported by Smith (2009).

\section{RESULTS}

The interviews were transcribed through reading and re-reading each interview in order to capture the quality and texture of individual experience (Smith, 2009). Emerging themes were identified and clustered within each transcription and then across the other cases (Smith, 2009). Summary themes were created and then analysed to identify clusters across all five interviews. An integrated table of themes (Table 1.) containing superordinate and subordinate themes was created with reference to each theme within the interview transcriptions. Transcriptions were analysed by the third author where there was a high degree of concordance suggesting inter-rater reliability

\section{'Baseline Behaviours Pre-Intervention'}

This superordinate theme describes the behaviours and characteristics that the BLIP participants exhibited before the intervention. This theme describes inadequate engagement throughout secondary school and behavioural issues inside and outside of school hours before year 11 .

\section{Subordinate Theme - 'Disengagement in School':}

This theme suggests that the BLIP participants had low academic interest before the BLIP and developed negative opinions of the school as stated by Participant 2 (p1: L 78-83):

"I hated school, I hated Swann Valley it wasn't a very nice place. Like I never got on with the teachers they didn't like me for some reason."

\section{Subordinate Theme - 'Behaviour Issues':}

This theme identified participant behaviour issues during and outside of school hours as suggested by Participant 4 (p1: L15 / p3: L91-93):

"I used to get into a lot of trouble before, especially with the police and the antisocial behaviour that goes on in my area."

'Immediate Outcomes of the BLIP'

The next set of themes related to the initial positive effects of the BLIP on its participants within the early stages of the programme.

\section{Subordinate Theme - 'Improved Attitude':}

This theme implied a change in attitude towards education amongst the participants as stated by Participant 5 (p4: L 130-133):

"I started wanting to do my work, and I looked forward to the basketball during the week." 
Subordinate Theme - 'Improved Focus':

This theme suggested that the participants developed a positive outlook on education through attending the BLIP as stated by Participant 1 (p8: L 235-237):

"I think with the basketball programme going on, it really helped me focus on the day, like when I had English, Maths and Science."

\section{Subordinate Theme - 'Immediate Outcomes of the BLIP':}

This theme showed positive engagement in the BLIP which contributed to an improved school experience and the willingness to utilise the intervention amongst the participants as said by Participant 3 (p5: L 152-154):

"I was really looking forward to it every week. It helped me and made me want to come to school!" 'Impact of the Coach'

This superordinate theme suggests that coachparticipant relationship was one of the most significant aspects of the programme. Furthermore, this relationship helped develop a sense of respect towards others amongst the participants.

\section{Subordinate Theme - 'Importance of Relationship':}

This theme contributed to a positive school and programme experience as stated by Participant 1 (p8: L 247):

'Obviously with you spending time with me, getting to know you better, that relationship. You're a good laugh and good mate and you help me out as well!"

\section{Subordinate Theme - 'Coach as a Role Model':}

This theme identifies the importance of the participants having someone to look up to which facilitates an improvement in attitude, academic achievement and behaviour as suggested Participant 5 (p7: L 237):

"Definitely a good role model for the people taking part. I definitely saw you as a good role model for me."

\section{Subordinate Theme - 'Respect':}

This theme refers to newly developed respect towards others amongst the participants. The theme, 'Baseline Behaviours Pre-Intervention', suggested that the participants lacked respect towards teachers and pupils. However, this theme shows the participant change in attitude during the intervention as stated by Participant 4 (p6: L 189): "Like I still went to school, it did motivate me for those other days because I know you would be expecting me to be in school and show respect towards others."

\section{'Long Standing Transferable Outcomes'}

This superordinate theme refers to the longitudinal effects of the BLIP as the participants were interviewed 12 months after the intervention and shows how the participants have used the BLIP experience on a daily basis.

\section{Subordinate Theme - 'Appreciation of Education':}

This theme refers to the participants feeling regret for not performing at school and how the participants are using these experiences to help others appreciate education as stated Participant 5 (p3: L 72-76):

"I'm definitely going to push it on my sister to do well in education. I can see now, coming out of school, education is the key to success. She needs to buckle down and get that done and I'm helping from my experience. Hopefully she'll listen."

\section{Subordinate Theme - 'Improved Behaviour':}

This theme refers to the changes in participant behaviour since leaving school and the BLIP 12 months ago. The participants show improved behaviour since the issues during the earlier years of education as supported by Participant 1 (p1: L 23-24):

"I don't get in trouble anymore. The programme helped me learn from my mistakes and I want to do better in life."

\section{Subordinate Theme - 'Purpose':}

This theme shows that the participants currently engage in positive environments since completing the programme and leaving school as stated by Participant 4 (p1: L 6-7):

"I got an apprenticeship to do train work. I've been working on the tracks trying to work my way up." 
Table 1. Integrated table of themes containing superordinate and subordinate themes

\begin{tabular}{|c|c|c|c|c|c|}
\hline \multicolumn{6}{|c|}{ Superordinate Theme: Baseline Behaviours Pre-Intervention } \\
\hline & Participant 1 & Participant 2 & Participant 3 & Participant 4 & Participant 5 \\
\hline \multicolumn{6}{|c|}{ Subordinate themes } \\
\hline $\begin{array}{l}\text { Disengagement } i \\
\text { school }\end{array}$ & $\begin{array}{r}\text { inP: 4.L: } 107-109 \\
\text { P: 6.L: 184-186 }\end{array}$ & P:3.L: 78-83 & $\begin{array}{l}\text { P:2.L: } 35-36 \\
\text { P:2.L: } 39-40 \\
\text { P:2.L: } 42\end{array}$ & P:1.L: 29 & P:1.L: $19-20$ \\
\hline Behaviour issues & $\begin{array}{l}\text { P: 2.L: } 41 \\
\text { P: 4.L: } 111\end{array}$ & $\begin{array}{l}\text { P:1.L: 22-23 / } \\
\text { P:3.L: 87-88 }\end{array}$ & P:4.L: 108 & $\begin{array}{l}\text { P:1.L: } 15 \\
\text { P:3.L: 91-93 }\end{array}$ & P:1.L: $33-35$ \\
\hline
\end{tabular}

Superordinate Theme: Immediate Outcomes of the BLIP

\begin{tabular}{|c|c|c|c|c|}
\hline & Participant 1 Participant 2 & Participant 3 & Participant 4 & Participant 5 \\
\hline \multicolumn{5}{|c|}{ Subordinate themes } \\
\hline \multirow[t]{2}{*}{$\begin{array}{l}\text { Improved } \\
\text { attitude }\end{array}$} & $\begin{array}{l}\text { P: 5.L: 143-P:5.L:148-149 } \\
145 /\end{array}$ & & P:5.L:148-149 & P:4.L:130-133 \\
\hline & $\begin{array}{l}\text { P: 6.L: 173- } \\
174\end{array}$ & & & \\
\hline Improved focus & P:8.L:235-237 P:5.L:151-152 & & P:5.L:144-145 & P:5.L:146-150 \\
\hline $\begin{array}{l}\text { Positive } \\
\text { engagementin } \\
\text { BLIP }\end{array}$ & P:8.L:226-227 P:5.L:133-135 & P:5.L:152-154 & P:5.L:139-141 & P:4.L:116-118 \\
\hline
\end{tabular}

\section{Superordinate Theme: Impact of the Coach}

\section{Subordinate themes}

$\begin{array}{lllll}\text { Participant } 1 & \text { Participant } 2 & \text { Participant } 3 & \text { Participant } 4 & \text { Participant } 5\end{array}$

\begin{tabular}{|c|c|c|c|c|c|}
\hline \multirow{3}{*}{$\begin{array}{l}\text { Importance } \\
\text { of relationship } \\
\text { Coach as a } \\
\text { role model } \\
\text { Respect }\end{array}$} & P:8.L: 247 & P:4.L: $123-124$ & \multicolumn{3}{|c|}{ P:5.L: 162-166 P:5.L: 128-130 P:4.L: 126-128 } \\
\hline & \multicolumn{2}{|c|}{ P:6.L: 160-162 P:8.L: 261} & P:9.L: 298 & P:6.L: 189 & P:7.L: 237 \\
\hline & P:10.L: 315 & P:5.L: 152 & P:9.L: 296 & P:6.L: 189 & P:5.L: $141-143$ \\
\hline \multicolumn{6}{|c|}{ Superordinate Theme: Long Standing Transferable Outcomes } \\
\hline & Participant 1 & Participant 2 & Participant 3 & Participant 4 & Participant 5 \\
\hline \multicolumn{6}{|c|}{ Subordinate themes } \\
\hline $\begin{array}{l}\text { Appreciation } \\
\text { of education }\end{array}$ & P:2.L: 39 & P:1.L: 27-29 & & P:1.L: 29-31 & $\begin{array}{l}\text { P:1.L: } 27-30 \\
\text { P:3.L: } 72-76\end{array}$ \\
\hline $\begin{array}{l}\text { Improved } \\
\text { behaviour }\end{array}$ & P:1.L: 23-24 & P:1.L:16 / L:22 & & $\begin{array}{l}\text { P:1.L: } 15-17 \\
\text { P:2.L: } 41\end{array}$ & P:1.L: 23-25 \\
\hline Purpose & $\begin{array}{l}\text { P:1.L: } \quad 6-7 \\
\text { L:9 }\end{array}$ & /P:1.L: 6-8 & P:1.L: 7-8 & P:1.L: 6-7 & \\
\hline
\end{tabular}

$\mathrm{L}=$ Line number from the original transcript. 


\section{DISCUSSION}

The participant behaviours before the intervention highlighted challenging behaviour and signs of disengagement within a school setting which is consistent with previous research. Poor student behaviour is common within highdelinquency rate secondary schools found in deprived communities in the (Hayden, 2011), (Farrington, 2005). Community deprivation leads to challenging behaviour amongst pupils within and outside the school setting (Higgins et al. 2010). The BLIP participants reside within Swanscombe, a deprived urban community (Kent County Council, 2011) that experiences high crime rates (UKCrimeStats, 2014).

Poor behaviour could have contributed to academic disengagement and poor academic performance amongst the participants before the BLIP as supported by Sandford et al. (2008). This could have led to a lack of positive stimulation in schools and therefore encouraged anti-social behaviour (Connor, 2012). It was important to investigate the immediate changes within these behaviours once the intervention began. The participants reported immediate impacts of the programme through improved attitude, focus and positive engagement in the BLIP. Hagger et al. (2011) identify a strong link between sport participation and cognitive functions with sport being especially beneficial to students with behavioural issues. The study implied that the participants exhibited improved behaviour in the early stages of the intervention through attendance, attitude and respect towards others within the school environment which can be linked to the cognitive functions mentioned by Hagger et al. (2011). These findings relate to sports interventions providing an immediate short-term impact on disengaged students as suggested by Sandford et al. (2008). Furthermore, the current study relates to research by Fujiwara et al. (2014) and Coalter (2005) in relation to physical activity providing an impact on social well-being as seen amongst the participants.

The study suggests that the participant involvement in basketball improved focus in relation to academic performance which highlights the impact of sport on academic achievement as suggested by the subordinate theme, 'improved focus'. The cognitive benefits of sport mentioned by Tomporowski et al. (2011) relate to the importance of positive stimulation for students mentioned by (Connor, 2012). The positive stimulation from the basketball sessions led to participants reporting improved focus at the beginning of the intervention. Lastly, the participants reported that improvements in behaviour and academic performance resulted from positive engagement in the BLIP. Morris et al. (2003) and Sandford et al. (2008) suggest that students improve in behaviour and learning when engaging in sports interventions which is supported in this study through themes of improvements in attitude, personality and focus. Active engagement within the programme supports the research by Tomporowski et al. (2011), Sandford et al. (2008) and Hagger et al. (2011) as participation in sport and positive stimulation (Connor, 2012) provide great benefit to the cognitive functions and development of secondary school students.

Results indicate that the role of the coach within the intervention was significant to the participants. The study suggests that one of the biggest benefits of the BLIP was the impact of the coach on the participants. Factors such as the importance of coach-participant relationship, the coach as a role model and developing respect for others were significant effects of the BLIP. However, the literature did not mention any of these factors within the sports interventions evaluated by Morris et al. (2003) and Sandford et al. (2008). Coach-participant relationship was very significant in terms of communication, expressing any issues and receiving support during the intervention. Athlete-coach relationships are very important in relation to athlete development (Beswick, 2010). However, the BLIP participants were not athletes and athlete development was not the purpose of the intervention. Nevertheless, the personal aspects of an athlete-coach relationship can apply to the relationship between the coach and the BLIP participants. Mutual care and relationship-orientated interactions are significant aspects of a successful relationship with the coach (Poczwardowski et al. 2002). The study supports this as the participants expressed care towards the coach by respecting instructions and engaging in the BLIP tasks. Furthermore, the data suggests that a positive relationship with the coach contributed 
to positive effects on the participants both within and outside of the school environment.

Seeing the coach as a role model during the BLIP was also a major factor that contributed to the positive impact of the intervention. Providing a role model for students can be seen in projects such as the 'Stay in School' initiative (Boston Celtics, no date). In contrast, most of the literature does not recognise the significance of role models during sports interventions. However, Bull and Beale (2012) identify the importance of the 'Fight For Peace' participants seeing the coach as a role model in order to successfully engage within the programme which relates to this study. Students are inspired by sports role models which leads to improved attitude and behaviour outside of the intervention environment (Biskup and Pfister, 1999) which shows that sports intervention participants can transfer a positive attitude into the outside world. This relates back to Hagger et al. (2001) in relation to behaviour improvements as a result of sports interventions.

Respect towards others was also a result of the coach impact highlighting the effects of sport participation on social skills (Lista and Sorrentino, 2010). Respect in terms of positive communication and behaviour is a social skill that can flourish through engagement in sports interventions (Fujiwara et al. 2014). Bull and Beale (2012) state that the 'Fight For Peace' programme contributed to the participants developing respect for the boxing coach which relates to this study with participant respect transferring to other aspects such as the school environment. This is the only longitudinal study measuring the impact of sportbased interventions on young people and should provide insight into the long-standing impact of such interventions.

The study shows a change of attitude towards education with participants regretting underperforming at school. Physical activity facilitates the development of cognitive functions amongst young people in terms of social skills, improving behaviour and positive engagement in school (Tomporowski et al. 2011), (Lista and Sorrentino, 2010), (Hagger et al. 2001) and (Sandford et al. 2008) which is seen amongst the BLIP members that have continued education following the intervention. However, it is difficult to determine how much of this change is a result of the current study, with a series of extraneous variables, such as maturity, possibly contributing to changes in participant behaviour.

The notion that participant behaviour can determine whether sport is successful in tackling anti-social behaviour is supported by (Sandford $e t$ al. 2008), (Morris et al. 2003) and (Bull and Beale, 2012). However, these studies fail to identify whether this is a long-term process following sports interventions. The current study indicates behaviour improvements at the beginning of the BLIP, which supports the short-term impact. Furthermore, the current study suggests improvement in participant behaviour postintervention which indicates longitudinal impact. However, the study took place 12 months after the intervention prompting enough time to elapse to consider whether changes were long standing. Nevertheless, most participants involved reported significant improvements in behaviour following the intervention.

Lastly, it is important to discuss what the participants have been engaged in since the intervention. A theme of purpose was revealed, which suggested the willingness get involved in something productive. The participants are engaging or seeking to get involved within a positive environment. The current study relates to research by Coalter (2005) and Fujiwara et al. (2014) and exemplifies sport being utilised as a social instrument with participants reporting longterm improvements in behaviour, attitude and social skills as a result of the BLIP.

\section{Conclusion}

The current study has produced an insight into how sports participation can influence disengaged young people through positive impacts on behaviour and education. The results were similar to other sports interventions aimed at reducing anti-social behaviour and re-engaging disengaged young people within a school. Exploring participant behaviours pre-intervention allowed the researcher to evaluate the immediate impact of the BLIP which related to literature examining short-term impacts of sports interventions. Participants improved in behaviour, academic performance and thoroughly engaged with the intervention. The BLIP provided a positive stimulation for the participants that was not present pre-intervention, which could have encourgaed anti-social behaviour. The study revealed an aspect of sports interventions that was hardly mentioned in surrounding literature. 
The role of the coach proved to be a significant part of the intervention for the participants. The BLIP coach provided a positive impact on the participants through mutual relationships and respect.

More importantly, this study evaluated the longitudinal effects of the BLIP making it the only research that examines the longitudinal impacts of sports interventions on disengaged young people. Furthermore, research suggested the need for a longitudinal qualitative approach in order to analyse the true effects of sports interventions once immersed into the outside world. It was necessary to evaluate if there were transferable personal development skills between the BLIP and general lifestyle amongst the participants. As a result; the study suggested a positive long-term impact of the BLIP amongst the participants as suggested by participant engagement in employment or further education.

\section{REFERENCES}

ADT. (2006) Anti-social behaviour across Europe. Available at: http://www.adt.co.uk/ antisocial.html (Accessed: 21 January 2014).

Beswick, B. (2010) Focused for soccer. 2nd edn. Human Kinetics.

Biskup, C. and Pfister, G. (1999) 'I would like to be like him/her: are athletes role-models for boys and girls?', European Physical Education Review, 5(3), pp. 199-218, Sage Journals [Online]. Available at: http://epe.sagepub.com/content/5/3/199.short (Accessed: 9 January 2014).

Boston Celtics (no date) Stay in school. Available at:http://www.nba.com/celtics/community/st ay_in_school.html (Accessed: 12 February 2014).

Bull, J.E., and Beale, J.T. (2012) 'A qualitative insight into the impact of a community based project on antisocial behaviour within a deprived urban area', in Gilbert, K. and

Bennett, W. (ed.) Sport, peace and development. Common Ground Publishing.

Coalter, F. (2005) The social benefits of sport: an overview to inform the community planning process. Edinburgh: sportscotland.

Connor, D.F. (2012) Aggression and antisocial behaviour in children and adolescents: research and treatment. Guildford Press.
Dagkas, S. and Stathi, A. (2007) 'Exploring social and environmental factors affecting adolescents' participation in physical activity', European Physical Education Review, 13(3), Sage Journals [Online]. Availableat:http://epe.sagepub.com/content/1 3/3/369. short (Accessed: 21 January 2014).

Farrington, D.P. (2005) 'Childhood origins of antisocial behaviour', Clinical Psychology \& Psychotherapy, 12(3), pp. 177-190, Wiley Online Library [Online]. Available at: http://onlinelibrary.wiley.com/doi/10.1002/c pp.448/abstract (Accessed: 4 March 2014).

Fujiwara, D., Kudrna, L., \& Dolan, P. (2014). Quantifying and valuing the wellbeing impacts of culture and sport. Department for Culture Media and Sport Research Paper.

Hagger, M.S., Chatzisarantis, N. and Biddle, S.J.H. (2001) 'The influence of self-efficacy and past behaviour on the physical activity intentions of young people', Journal of Sports Sciences, 9(19), pp. 711-725, Taylor $\&$ Francis [Online]. Available at: http://www.tandfonline.com/doi/abs/10.1080 /02640410152475847\#.Ut6QhyiQG-U

(Accessed: 24 January 2014).

Hartman, D. and Debro, B. (2006) 'Rethinking sports-based community crime prevention a preliminary analysis of the relationship between midnight basketball and urban crime stats', Journal of Sport \& Social Issues, 30(2), pp. 180-196, Sage Journals [Online].Availableat:http://jss.sagepub.com/ content/30/2/180.short (Accessed 7 February 2014).

Hayden, C. (2011) Crime, anti-social behaviour and schools in Britain - are all schools 'at risk'?. Institute of Criminal Justice Studies.

Higgings, N., Robb, P. and Britton, A. (2010) Crime in England and Wales 2009/10. Availableat:https://www.gov.uk/government/ uploads/system/uploads/attachment_data/file /116360/hosb1210-chap7.pdf (Accessed: 22 January 2014).

Houlihan, B. and Green, M. (2013) Routledge handbook of sports development. Routledge. Kelley, B. and Carchia, C. (2013) Hey, data data - swing! the hidden demographics of youthsports.Availableat:http://espn.go.com/e spn/story/_id/9469252/hiddendemographics -youth-sports-espn-magazine (Accessed 21 February 2014). 
Kent County Council (2011) The indices of deprivation 2010: detailed findings for Kent. Research \& Evaluation Report, Kent County Council.

Kent Independent Education Advice (2013) The tribulations of Swan Valley School, Swanscombe.Availableat:http://www.kentad vice.co.uk/peters-blog/news-a comments /item/500-the-tribulations-ofswan-valleyschool-swanscombe.html (Accessed: 5 January 2014).

Kent Online (2012) Head teacher quits school. Availableat:http://www.kentonline.co.uk/dar tford_messenger/news/2012/november/21/he ad_teacher_quits_school.aspx (Accessed: 5 January 2014).

Lista, I. and Sorrentino, G. (2010) 'Biological mechanisms of physical activity in preventing cognitive decline', Cellular and Molecular Neurobiology, 30(4), pp. 493-503, Springer Link [Online]. Available at: http://link.springer.com/article/10.1007/s105 71-009-9488-x (Accessed: 3 February 2014).

Morris, L., Sallybanks, J., Willis, K., and Makkai, T. (2003) 'Sport, physical activity and anti social behaviour in youth', Australian Institute of Criminology: trends \& issues, No. 249.

Oransky, M. and Maracek, J. (2009) 'I'm not going to be a girl masculinity and emotions in boys' friendships and peer groups', Journal of Adolescent Research, 24(2), pp. 218-241, Sage Journals [Online]. Available at:http://jar.sagepub.com/content/24/2/218.sh ort (Accessed: 12 January 2014).

Poczwardowski, A., Barott, J.E. and Henschen, K.P. (2002) 'The athlete and coach: their relationship and its meaning. results of and interpretive study', International Journal of Psychology, 33(1), American Psychology Association [Online]. Available at: http://psycnet.apa.org/psycinfo/2002-13927008 (Accessed: 2 February 2014).

Sandford, R.A., Duncombe, R. and Armour, K.M. (2008) 'The role of physical activity/sport in tackling youth disaffection and anti-social behaviour', Educational Review, 60(4), pp. 419-435.

Scensul, S.L. (1999) Essential ethnographic methods: observations, interviews and questionnaires. Rowman Altamira.
Smith,J.A. (2009) Interpretative phenomenological analysis: theory, method and research. Sage Publications.

Tomporowski, P.D., Lanbourne, K. and Okumura, M.S. (2011) 'Physical activity interventions and children's mental functions: an introduction and overview', Preventive Medicine, 52(1), pp. S3-S9, ScienceDirect [Online].Availableat:http://www.sciencedire ct.com/science/article/pii/S00917435110005 69 (Accessed: 3 January 2014).

UKCrimeStats (2014) Dartford-Swanscombe. Availableat:http://www.ukcrimestats.com/ $\mathrm{Ne}$ ighbourhood/Kent_Police/Dartford_Swansc ombe (Accessed: 2 February 2014)

How to cite this article: Volskis L., Hunt, R. and Beale J.T. (2020). A Qualitative Investigation Into the Impact of the Basketball Learning Intervention Programme (BLIP) on Disengaged Secondary School Students in the United Kingdom. Int J Disabil Sports Health Sci;3(1):11-19.

https://doi.org/10.33438/ijdshs.730528 